\title{
Emodin Inhibits the Proliferation of MCF-7 Human Breast Cancer Cells Through Activation of Aryl Hydrocarbon Receptor (AhR)
}

\author{
Ning Zhang ${ }^{1,2,3 \dagger}$, Jiawen Wang ${ }^{4 \dagger}$, Aimin Sheng ${ }^{2}$, Shuo Huang ${ }^{5}$, Yanyan Tang ${ }^{5}$, Shitang Ma ${ }^{1 *}$ \\ and Ge Hong ${ }^{3 *}$
}

${ }^{1}$ Life and Health College, Anhui Science and Technology University, Fengyang, China, ${ }^{2}$ School of Chemical Engineering, Anhui University of Science and Technology, Huainan, China, ${ }^{3}$ Tianjin Key Laboratory of Biomedical Materials, Institute of Biomedical Engineering, Chinese Academy of Medical Science and Peking Union Medical College, Tianjin, China, ${ }^{4}$ School of Pharmacy, East China University of Science and Technology, Shanghai, China, ${ }^{5}$ Clinical College of Orthopedics, Tianjin Medical University, Tianjin Hospital, Tianjiin, China

\section{OPEN ACCESS}

Edited by:

Syed Nasir Abbas Bukhari, Al Jouf University, Saudi Arabia

Reviewed by: Masoud Rezvanian, National University of Malaysia, Malaysia

Hesham M. Korashy, Qatar University, Qatar

*Correspondence:

Shitang Ma

mast@ahstu.edu.cn

Ge Hong

hongge@bme.pumc.edu.cn

${ }^{t}$ These authors have contributed equally to this work

Specialty section:

This article was submitted to Experimental Pharmacology and Drug Discovery,

a section of the journal

Frontiers in Pharmacology

Received: 27 October 2020 Accepted: 15 December 2020

Published: 19 January 2021

Citation:

Zhang N, Wang J, Sheng A, Huang S, Tang Y, Ma S and Hong G (2021) Emodin Inhibits the Proliferation of MCF-7 Human Breast Cancer Cells

Through Activation of Aryl

Hydrocarbon Receptor (AhR).

Front. Pharmacol. 11:622046.

doi: 10.3389/fphar.2020.622046
Natural products have proved to be a promising source for the development of potential anticancer drugs. Emodin, a natural compound from Rheum palmatum, is used to treat several types of cancers, including lung, liver, and pancreatic. However, there are few reports regarding its use in the treatment of breast cancer. Thus, the therapeutic effect and mechanism of emodin on MCF-7 human breast cancer cells were investigated in this study. Morphological observations and cell viability were evaluated to determine the antiproliferation activity of emodin. Network pharmacology and molecular docking were performed to screen the potential targets. Western blot analysis was used to explore a potential antitumor mechanism. The results showed that emodin $(50-100 \mu \mathrm{mol} / \mathrm{L})$ could significantly inhibit the proliferation of MCF-7 cells in a time and dose-dependent manner. Furthermore, virtual screening studies indicated that emodin was a potent aryl hydrocarbon receptor (AhR) agonist in chemotherapy for breast cancer. Finally, when MCF-7 cells were treated with emodin $(100 \mu \mathrm{mol} / \mathrm{L})$ for $24 \mathrm{~h}$, the AhR and cytochrome P450 1A1 (CYP1A1) protein expression levels were significantly upregulated compared with the control group. Our study indicated that emodin exhibited promising antitumor activity in MCF-7 cells, likely through activation of the AhR-CYP1A1 signaling pathway. These findings lay a foundation for the application of emodin in breast cancer treatment.

Keywords: emodin, AhR, CYP1A1, breast cancer, MCF-7, network pharmacology

\section{INTRODUCTION}

Breast cancer is one of the most common malignant tumors that seriously threaten women's health worldwide (Jia et al., 2015). Although screening for breast cancer is gradually being more regularly performed, incidence of the disease is still increasing year by year. According to the latest data from the International Agency for Research on Cancer (IARC) in 2018, breast cancer ranks first among female cancers worldwide with an incidence rate of $24.2 \%$. Notably, $52.9 \%$ of these breast cancer cases occur in developing countries and seriously threaten the lives of the patients (Ferlay et al., 2019). With the increasing incidence of breast cancer in women, surgery is currently the main clinical treatment, but adjuvant chemotherapy is also widely used in breast cancer patients. These treatment 
strategies are relatively expensive. For example, the cost of breast cancer care in the United States in 2020 was predicted to be $\$ 19$ billion (Mariotto et al., 2011). Due to its high incidence, breast cancer treatment accounts for the largest proportion of total expenditures of all cancers (Pickle et al., 2007). In addition, there is a high risk of operation failure. If not handled properly, this will endanger the life of the patient. Additionally, surgical treatment can damage the physical and mental health of female patients. Chemotherapy may cause breast cancer cells to develop multi-drug resistance (MDR), leading to therapeutic failure (Khongkow et al., 2016b). Anthracyclines, paclitaxel, and their semi-synthetic derivatives have achieved good results in the treatment of breast tumors after surgery. However, the adverse reactions of anthracyclines and taxanes, especially hematological adverse reactions (myelosuppression) and drug resistance, negatively affected effective application of these drugs. These side effects were also one of the common reasons for the failure of breast cancer chemotherapy (Khongkow et al., 2016a). Therefore, discovery of effective adjuvant therapy and alternative therapy drugs has become a key focus in postoperative treatment research for breast cancer.

Emodin is a natural anthraquinone compound with antitumor activity and is obtained from the separation and purification of Chinese medicine Rheum palmatum, Polygonum cuspidatum, and Aloe vera Berg (Yang et al., 2014a). Like the anti-tumor drug mitoxantrone and antibiotic daunorubicin, emodin has no amino sugar structure or free radicals, so it has minimal adverse reactions in patients. Emodin can also induce DNA fragmentation in cancer cells (Xing et al., 2015). It has been reported that emodin has anti-inflammatory, anti-bacterial, and anti-tumor effects. Currently, published studies have focused on the role of emodin in the following cancers: ovarian cancer (Li et al., 2009; Lu et al., 2017), lung cancer (Ko et al., 2010), chronic myeloid leukemia (Chun-Guang et al., 2010), and sensitizing gastric cancer (Cai et al., 2008). For the treatment of breast cancer, some researchers have studied the estrogen receptor alpha-mitogen-activated protein kinases/Akt-cyclin D1/B-cell lymphoma-2 signaling pathway (Sui et al., 2014), regulation of myeloid cell leukemia-1, cyclin D1, and C-myc genes (Li et al., 2013), and more (Sun et al., 2015; Zu et al., 2015). However, there are few studies on emodin-mediated regulation of the AhR target of breast cancer. The potential anti-tumor and immune regulation mechanisms of emodin have become a new research hotspot.

Our study was performed to explore the mechanism by which emodin acts on breast cancer cells through a comprehensive network pharmacology and experimental approach, which proved that emodin can activate AhR to inhibit the proliferation of MCF-7 cells and promote apoptosis. This provided a basis for the clinical application of emodin and provided a reference for further research in the future.
- Chemicals and materials.

- Cell morphology observations.

- Cell proliferation was detected by MTT assay.

- Flow cytometric analysis of apoptosis.

- Chemical structure information and pharmacokinetic parameters of Emodin.

- Emodin target prediction by network pharmacology.

- Construction of Protein-Protein interaction (PPI) network.

- GO and KEGG pathways enrichment analyses.

- Molecular docking study.

- Western blot analysis. The research flowchart is shown in Figure 1.

\section{Chemicals and Materials}

Emodin was purchased from Shanghai Yuanye Bio-Technology Co., Ltd. (Shanghai, China, HPLC $\geq 98 \%$, Lot: P02N6F5299), dissolved in dimethyl sulfoxide (DMSO) to prepare a stock solution of $1 \mathrm{mmol} / \mathrm{L}$, and was stored at $-20^{\circ} \mathrm{C}$. MCF-7 cells were obtained from the Institute of Biomedical Engineering, Chinese Academy of Medical Sciences (Tianjin, China). For cell culture, Dulbecco's Modified Eagle Medium (DMEM) was purchased from ThermoFisher Biochemical Products Co., Ltd. (Beijing, China). Fetal bovine serum (FBS) and phosphatebuffered saline (PBS) were purchased from Biological Industries Israel Beit Hemek Ltd (Kibbutz Beit Hamek, Israel). Streptomycin $(100 \mu \mathrm{g} / \mathrm{ml})$ and Penicillin (100 units/mL) were purchased from Life Technologies Corporation (New York, United States). The AhR antibody was purchased from Affinity Biosciences (Columbus, United States, Cat. No. AF6278) and the CYP1A1 antibody was purchased from Wuhan Sanying Biotechnology Co., Ltd. (Wuhan, China, Cat. No. 13241-1-AP). The secondary goat anti-rabbit antibody was purchased from Invitrogen Corporation (Carlsbad, United States). The glyceraldehyde phosphate dehydrogenase (GAPDH) antibody was obtained from Kangchen BioTechnology Co., Ltd. (Shanghai, China).

\section{Cell Culture}

MCF-7 cells were cultured in DMEM supplemented with $10 \%$ FBS and $1 \%$ penicillin-streptomycin. The cultures were incubated at $37^{\circ} \mathrm{C}$ in a humidified atmosphere containing $5 \%$ carbon dioxide. The medium was changed every two days and cells were passaged at a dilution of 1:4.

\section{Cell Morphology Observations}

For the morphological observation of MCF-7 cells, 300,000 cells were seeded in a 6-well plate at 50,000 cells per well. Cells were treated with emodin at concentrations of $0 \mu \mathrm{mol} / \mathrm{L}, 25 \mu \mathrm{mol} / \mathrm{L}$, $50 \mu \mathrm{mol} / \mathrm{L}$, and $100 \mu \mathrm{mol} / \mathrm{L}$. After incubating for $24 \mathrm{~h}$, the cells were observed and pictures were taken using an Inverted Fluorescence Microscope (Nikon, Tokyo, Japan) in the visual field at $200 \times$.

\section{MTT Assay Detect Cell Proliferation}

MCF-7 cell proliferation rates were evaluated by MTT assay. Cells were plated in two 96-well plates at a density of $10^{5}$ cells $/ \mathrm{mL}$ and

This study includes the main steps as follows: 


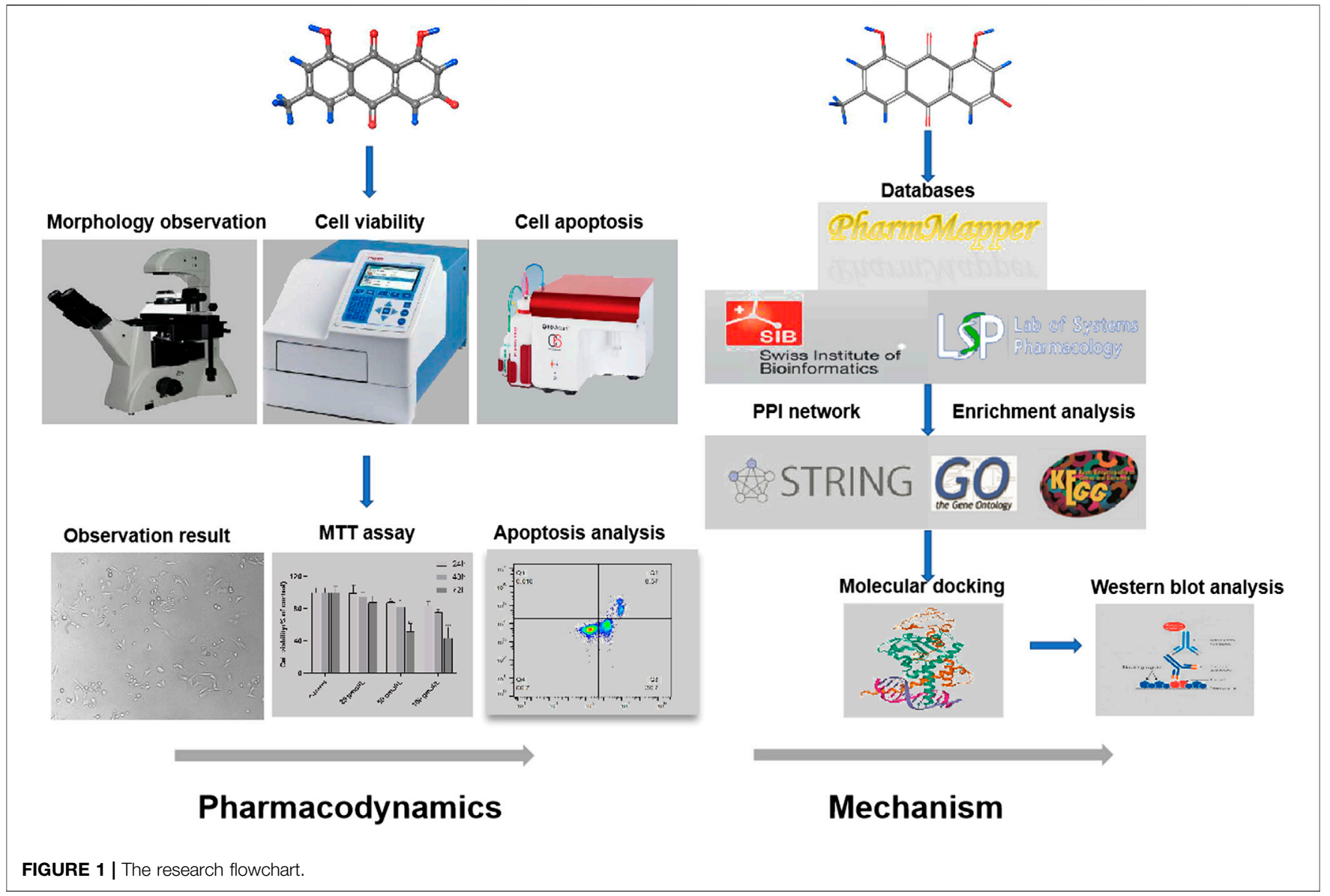

cultured for $24 \mathrm{~h}$. Cells were treated with different concentrations of emodin $(0,25,50$, and $100 \mu \mathrm{mol} / \mathrm{L})$ and different concentrations of emodin $(0,25,50$, and $100 \mu \mathrm{mol} / \mathrm{L})$ containing $10 \mu \mathrm{mol} / \mathrm{L}$ of $\mathrm{AhR}$ inhibitor (CH223191) (Eleftheriadis et al., 2016; Miliutina et al., 2017). After 24, 48, and $72 \mathrm{~h}$ of treatment, $50 \mu \mathrm{L}$ of MTT reagent $(1 \mathrm{mg} / \mathrm{ml})$ was added, and the cells were then incubated for another $4 \mathrm{~h}$. The culture medium was removed and the formazan crystals were dissolved in $150 \mu \mathrm{L}$ of DMSO. The absorbance was measured at $490 \mathrm{~nm}$ by a multifunctional microplate spectrophotometer (Thermo Varioskan Flash 3,001, Waltham, MA, United States). The experiment was repeated three times and the mean value was taken. Cell viability rate $=$ treatment group value/control group value $\times 100 \%$.

\section{Flow Cytometric Analysis of Apoptosis}

Apoptosis rates of MCF-7 cells were evaluated by an Annexin V-FITC/PI apoptosis detection kit (Beyotime Institute of Biotechnology, Shanghai, China). In general, MCF-7 cells were processed into a single cell suspension, counted and seeded in two 6-well plates, and incubated for $24 \mathrm{~h}$ at $37^{\circ} \mathrm{C}$. The cells were then treated with different concentrations of emodin alone $(0,25,50,100 \mu \mathrm{mol} / \mathrm{L})$ or different concentrations of emodin containing $10 \mu \mathrm{mol} / \mathrm{L}$ of $\mathrm{CH} 223191$. After $72 \mathrm{~h}$ of incubation, the cells were washed twice with cold PBS, digested with $0.25 \%$ trypsin (without ethylenediaminetetraacetic acid), transferred to a $15 \mathrm{ml}$ centrifuge tube, and centrifuged at $1,000 \mathrm{rpm}$ for $5 \mathrm{~min}$, after which the supernatant was discarded. Next, $5 \times 10^{5} / \mathrm{ml}$ cells were collected and gently resuspended in $195 \mu \mathrm{L}$ of Annexin V-FITC binding buffer, followed by the addition of $5 \mu \mathrm{L}$ of Annexin V-FITC and $10 \mu \mathrm{L}$ of PI and then mixed evenly. After samples were covered with aluminum foil and incubated for $15 \mathrm{~min}$ at room temperature in the dark, they were placed in an ice bath and the cell apoptosis rates were detected using flow cytometry (CyFlow ${ }^{\circledR}$ Cube 6, Sysmex). Data are shown as pseudo color graphs and were analyzed using FlowJo Software (Tree Star Inc, Ashland, OR, Unites States).

\section{Chemical Structure Information and Pharmacokinetic Parameters of Emodin}

Chemical structure information for emodin was obtained from the NCBI PubChem database (https://www.ncbi.nlm.nih.gov/ pccompound/?term=emodin, PubChem CID: 3220). Absorption, distribution, metabolism, and excretion (ADME) as standards of pharmacokinetic parameters were obtained from the Traditional Chinese Medicine Systems Pharmacology 
(TCMSP) (https://tcmspw.com/molecule.php?qn=472) database to evaluate the pharmacokinetic features of emodin ( $\mathrm{Ru}$ et al., 2014).

\section{Emodin Target Prediction by Network Pharmacology}

To acquire potential targets, we used "emodin" as a keyword to search. All targets of the drug were screened out by the PharmMapper, Swiss Target Prediction, and TCMSP databases. The PharmMapper database (http://www.lilab-ecust.cn/ pharmmapper/) is an open-access web server designed for identifying potential targets for a given molecule through the pharmacophore mapping approach (Wang et al., 2017). The Swiss Target Prediction database (http://www. swisstargetprediction.ch/) allows for estimation of the most probable macromolecular targets of a small molecule with a library of 370,000 known active sites of more than 3,000 proteins from three different species (Gfeller et al., 2014). The TCMSP database (https://tcmspw.com/molecule.php?qn=1097) is a unique pharmacology platform of Chinese herbal medicines that captures the relationships between drugs, targets, and diseases ( $\mathrm{Ru}$ et al., 2014). Through combining the three databases, the most likely biological targets of emodin were predicted and the Universal Protein (Uniprot) database (https://www.uniprot.org/) was used to seek the UniProt Knowledgebase (UniProtKB), gene symbol, and gene ID (Bairoch et al., 2005).

\section{Construction of Protein-Protein Interaction (PPI) Network}

PPI is the binding that occurs between protein molecules to form protein complexes by non-covalent bonds (De Las and Fontanillo, 2010; Athanasios et al., 2017). Firstly, the targets were entered into the STRING database (Szklarczyk et al., 2017) (https://string-db.org/) to perform the protein interaction analysis and visualization. The species was limited to Homo sapiens, a confidence level greater than 0.7 was retained, and the tsv. format of the PPI network results was downloaded. In the network, nodes represented the targets and edges represented interactions between the targets and compounds.

\section{GO and KEGG Pathway Enrichment Analyses}

Gene Ontology (GO) analysis (http://geneontology.org/) was performed, which included biological process (BP), molecular function (MF), and more (Gaudet and Dessimoz, 2017). Kyoto Encyclopedia of Genes and Genomes (KEGG) pathway analysis (Zhang et al., 2019) (https://www.kegg.jp/) was also performed, which can identify the functional role and potential biological correlation of candidate targets. The DAVID database (https:// david.ncifcrf.gov/) was used to enrich GO and KEGG pathways. After the enrichment was completed, $\mathrm{R}$ software was used to analyze and visualize the results.

\section{Molecular Docking Study}

A molecular docking simulation was carried out using Glide modules of Schrödinger suite 2009 (Schrödinger LLC, New York, United States) (Friesner et al., 2006). In the absence of a crystalized structure of AhR-LBD, the structurally related PAS-B domain of HIF2a (PDB ID: 3F1O) was used for molecular docking analysis. Initially, the proteins were prepared using the "protein preparation wizard" including preprocessing, reviewing, modification, and refinement. In these steps, hydrogen atoms were added and all bound water molecules were removed from the protein (Sastry et al., 2013; Shaik et al., 2016). Subsequently, protein optimization was done utilizing a reorienting hydrogen bond network and minimizing the energy using the OPLS2005 force field (Harder et al., 2016). The structure of emodin was constructed using the Mastro workspace build panel and energetically minimized with the OPLS2005 force field using the ligand minimization tool. The receptor grid was generated around the native ligand with the center coordinates $2 \mathrm{XY}(\mathrm{x}=19.09, \mathrm{y}=-30.43, \mathrm{z}=8.86)$ and the size of the grid box was set to $20 \AA$. Other default parameters were involved in the docking calculations and all calculations were performed using Extra Precision (XP) model (Mangiatordi et al., 2017). The Pose Viewer panel was employed to visualize the interactions between emodin and amino acid residues of the model protein, as well as between $\mathrm{CH} 223191$ and the amino acid residues of the model protein.

\section{Western Blot Analysis}

A protein lysis solution was used to extract total protein from treated MCF-7 cells. Protein concentrations were detected using a BCA assay kit. Proteins $(20 \mu \mathrm{g})$ were resolved by $10 \%$ sodium dodecyl sulfate-polyacrylamide (SDS-PAGE) gel electrophoresis, followed by transfer onto polyvinylidene difluoride (PVDF) membranes and blocking with $10 \%$ Tris-buffered saline and Tween 20 (TBST) for $1.5 \mathrm{~h}$ at room temperature. Membranes were sealed with $5 \%$ skim milk powder sealant at room temperature for $2 \mathrm{~h}$, then washed with TBST twice. The membranes were then incubated overnight at $4^{\circ} \mathrm{C}$ with the appropriate primary antibody (AhR or CYP1A1) at a 1:1000 dilution. Finally, the membranes were incubated for $1 \mathrm{~h}$ with the goat anti-rabbit IgG secondary antibody at a 1:10,000 dilution and washed three times with TBST.

\section{Statistical Analysis}

SPSS 19.0 statistical software was used to perform experimental data analysis. The data are expressed as the mean \pm standard deviation (SD). The difference between each group was compared with one-way variance analysis and comparison of cell absorbance values was used in repeated measurement analysis of variance. $p<0.05$ indicated that the difference was statistically significant. Differences in protein expression between the individual groups were analyzed using a $t$-test with Graphpad Prism eight software and used to make column charts. 


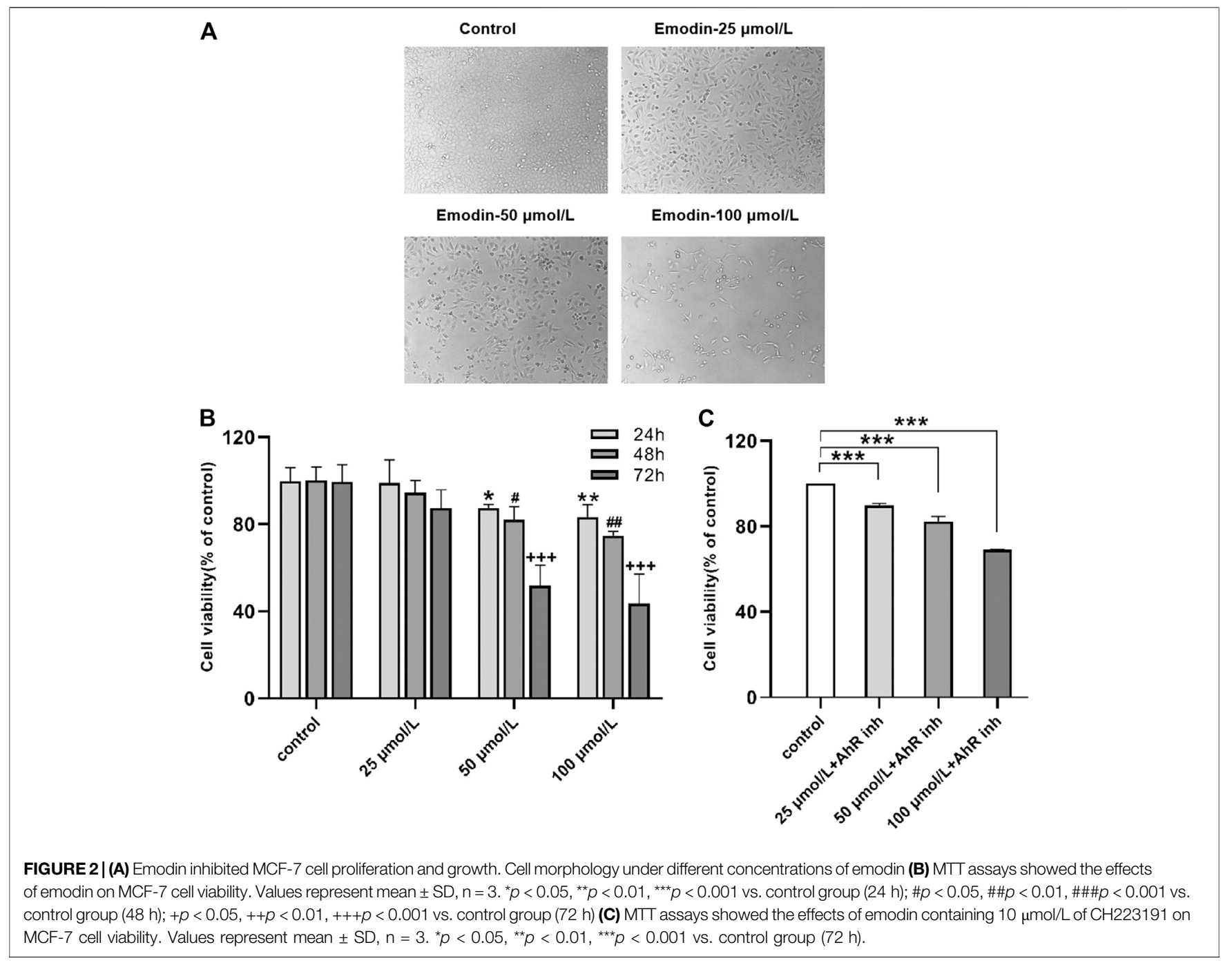

\section{RESULTS}

\section{Morphological Observations of MCF-7 Cells}

When viewed with an inverted fluorescence microscope, the MCF-7 cells grew vigorously and appeared mostly oval in shape with intact cell bodies in the normal control group. After treating the MCF-7 cells with increasing concentrations of emodin and longer exposure times, the number of living cells was significantly reduced, the cytoplasm size shrank, and the cells were no longer connected to fragments (Figure 2A), the results proved that emodin can cause cell death.

\section{Cell Proliferation Detected by MTT Assay}

The effects of emodin on the activity of MCF-7 cells were detected by MTT assay. The results indicated that treating MCF-7 cells with different concentrations of emodin resulted in reduced cell proliferation rates. Interestingly, the inhibitory effect of emodin on the proliferation of MCF-7 cells was both time-dependent and concentration-dependent. After treating the cells with emodin, the time of maximum inhibition occurred at $72 \mathrm{~h}$ and the concentration of maximum inhibition was $100 \mu \mathrm{mol} / \mathrm{L}$ (Figure 2B). Next, we co-treated the cells with different emodin concentrations and $10 \mu \mathrm{mol} / \mathrm{L}$ of $\mathrm{AhR}$ inhibitor for $72 \mathrm{~h}$. The inhibitory effect of emodin on cell proliferation was weakened when the cells were co-treated with the inhibitor (Figure 2C). These experimental results suggested that emodin inhibited the proliferation of breast cancer cells by activating on AhR.

\section{Flow Cytometric Analysis of Apoptosis}

To investigate if the cell death induced by emodin was related to apoptosis, the interaction of MCF-7 cells with emodin was further analyzed by annexin V-FITC/PI staining, and the apoptosis ratios were detected by flow cytometry. After $72 \mathrm{~h}$ of incubation with emodin, cells were collected for apoptosis analysis. As shown in Figure 3, after exposure to different concentrations of emodin $(25,50$, and $100 \mu \mathrm{mol} / \mathrm{L})$ in MCF-7 cells, the amount of apoptotic cells (including the early and late apoptosis ratios) increased gradually from $0 \%$ relative to the control to $39.27,58.7$, and 

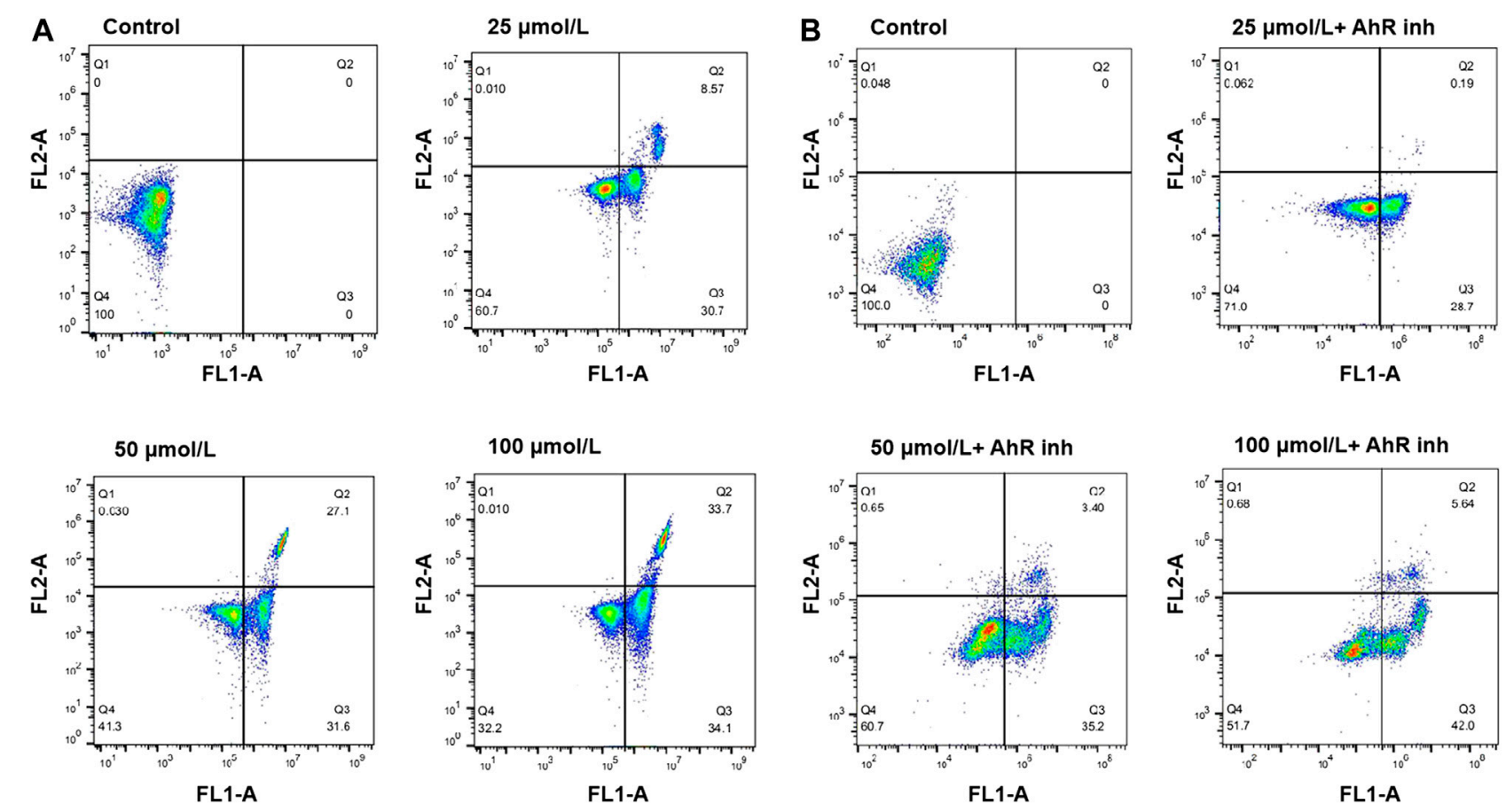

FIGURE 3 | (A) Flow cytometry analysis of apoptosis using Annexin V-FITC/PI double staining in MCF-7 cells treated with emodin at the indicated concentrations for $72 \mathrm{~h}$ (B) Flow cytometry analysis of apoptosis using Annexin V-FITC/PI double staining in MCF-7 cells treated with emodin at the indicated concentrations or emodin with containing $10 \mu \mathrm{mol} / \mathrm{L}$ of $\mathrm{CH} 223191$ for $72 \mathrm{~h}$. The percentage of cells is shown in the respective quadrants.
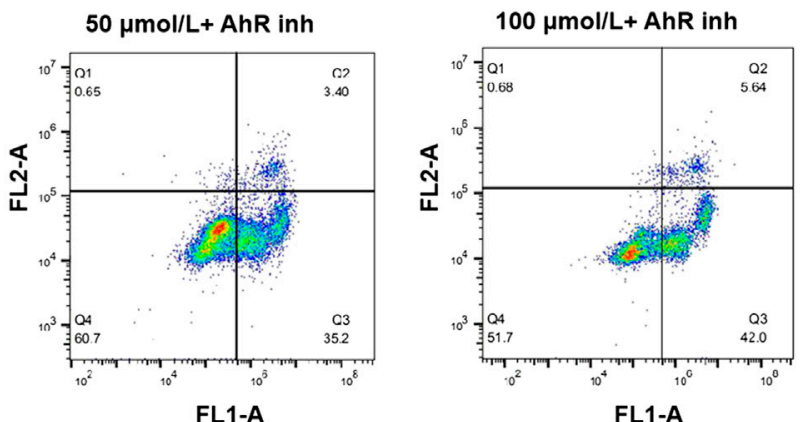

FL1-A

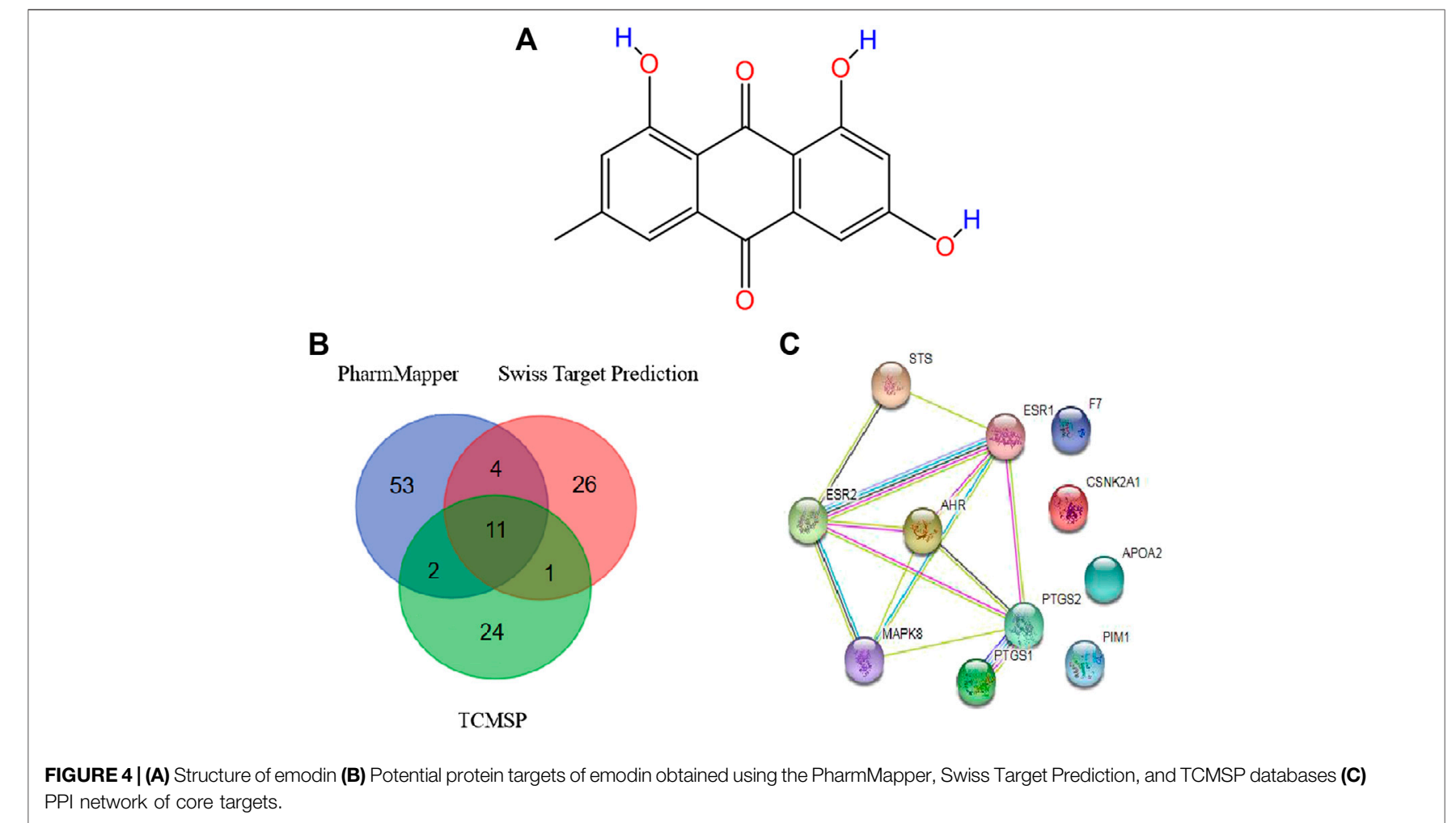


TABLE 1 | Properties of emodin.

\begin{tabular}{lccccc}
\hline Name & MW & AlogP & Caco-2 & OB(\%) & DL \\
\hline Emodin & 270.25 & 2.49 & 0.22 & 24.40 & 0.24
\end{tabular}

MW: Molecular weight, AlogP: Predicted octanol/water partition coefficient, Caco-2:

Predicted apparent Caco-2 cell permeability, OB: oral bioavailability, DL: drug-likeness.

$67.8 \%$, at the three respective concentrations. When MCF-7 cells were exposed to different concentrations of emodin $(25,50$, $100 \mu \mathrm{mol} / \mathrm{L})$ together with $10 \mu \mathrm{mol} / \mathrm{L}$ of $\mathrm{CH} 223191$, the apoptotic cells (including the early and late apoptosis ratios) increased gradually from $0 \%$ relative to the control to $28.89,38.6$, and $47.64 \%$, respectively. These results showed that emodin could inhibit the proliferation of breast cancer cells through apoptosis pathway.

\section{Chemical Structure and Pharmacokinetic Parameters of Emodin}

The chemical structure information of emodin was obtained from the NCBI PubChem database (Figure 4A), which showed an orange-yellow long needle-like crystal (crystal in acetone was orange, crystal in methanol was yellow). As shown in Table 1, the numerical values of the pharmacokinetic parameters of emodin were acquired by entering the CAS number of emodin into the TCMSP server. The combination of oral bioavailability (OB) screening and drug-likeness (DL) performance evaluation has been widely used to screen properties of compounds (Tian et al., 2015). The OB and DL of emodin were evaluated and showed a high DL value of 0.24 , which is higher than the average DL value of 0.18 . Therefore, emodin may be a promising drug. Previous studies reported that emodin could act on the digestive and circulatory systems through pharmacological effects including regulation of gastrointestinal function, cardio-cerebrovascular protection, anti-tumor effects, and immune regulation. Therefore, by examining potential targets of emodin, we explored the effects of using this compound on MCF-7 cells and its mechanism of action.

\section{Target Acquisition}

Data were collected by a comprehensive predictive method from three databases, including PharmMapper, Swiss Target Prediction, and TCMSP. Duplicates were removed, a total of 70 potential targets were obtained from the PharmMapper data, and a total of 42 potential targets were obtained from the Swiss Target Prediction data. Meanwhile, we obtained a total of 38 potential targets from the TCMSP data. To improve the specificity of the target protein, we selected 11 interrelated protein targets as candidates for further research by combining the above three databases (Table 2). According to the candidate targets, a Venn diagram was generated (Figure 4B).
TABLE 2 | Interrelated protein target information.

\begin{tabular}{|c|c|c|c|c|}
\hline Rank & UniProtKB & $\begin{array}{l}\text { Gene } \\
\text { symbol }\end{array}$ & $\begin{array}{l}\text { Gene } \\
\text { ID }\end{array}$ & Protein name \\
\hline 1 & P45983 & MAPK8 & 5,599 & $\begin{array}{l}\text { Mitogen-activated protein } \\
\text { kinase } 8\end{array}$ \\
\hline 2 & P08842 & STS & 412 & Steryl-sulfatase \\
\hline 3 & P03372 & ESR1 & 2,099 & Estrogen receptor alpha \\
\hline 4 & Q92731 & ESR2 & 2,100 & Estrogen receptor beta \\
\hline 5 & P23219 & PTGS1 & 5,742 & Prostaglandin $\mathrm{G} / \mathrm{H}$ synthase 1 \\
\hline 6 & P35354 & PTGS2 & 5,743 & Prostaglandin G/H synthase 2 \\
\hline 7 & P35869 & AhR & 196 & Aryl hydrocarbon receptor \\
\hline 8 & P02652 & APOA2 & 336 & Apolipoprotein A-II \\
\hline 9 & P11309 & PIM1 & 5,292 & $\begin{array}{l}\text { Serine/threonine-protein } \\
\text { kinase PIM1 }\end{array}$ \\
\hline 10 & P08709 & $\mathrm{F} 7$ & 2,155 & Coagulation factor VII \\
\hline 11 & P68400 & CSNK2A1 & 1,457 & Casein kinase II subunit alpha \\
\hline
\end{tabular}

\section{Construction of a Protein-Protein Interaction (PPI) Network}

To develop a better understanding of the association between potential protein targets, the candidate targets were imported into the STRING database to obtain their potential interaction relationships. The interaction network had 11 nodes and 13 edges. However, only seven targets were interconnected among these candidate targets: Mitogen-activated protein kinase 8 (MAPK8), Aryl hydrocarbon receptor (AhR), Estrogen receptor alpha (ESR1), Prostaglandin G/H synthase 2 (PTGS2), Steryl-sulfatase (STS), Prostaglandin G/H synthase 1 (PTGS1), and Estrogen receptor beta (ESR2) (Figure 4C). Therefore, these top seven targets of high-node degrees were considered as the key targets and were the focus of further research.

\section{GO and KEGG Pathway Enrichment Analyses}

To further investigate the anti-tumor mechanisms of emodin, GO biological function annotation and KEGG signal pathway analyses were carried out on 11 key targets using the DAVID Bioinformatics Resources 6.8 software. GO results showed that the intersection gene set was enriched in 205 biological process pathways and 32 processes related to molecular function (Figure 5A). The 12 KEGG pathways were obtained after running 11 common targets in $\mathrm{R}$ language. The results were displayed as a bar graph of KEGG function enrichment, as shown in Figure 5B, and showed that common targets were mainly enriched in the prolactin signaling pathway, endocrine resistance, estrogen signaling pathway, and breast cancer, among other pathways. Through a literature search, we found that the AhR protein plays an important role in the abovementioned diseases. Therefore, we chose AhR as the key target of emodin in breast cancer for more in-depth research. 


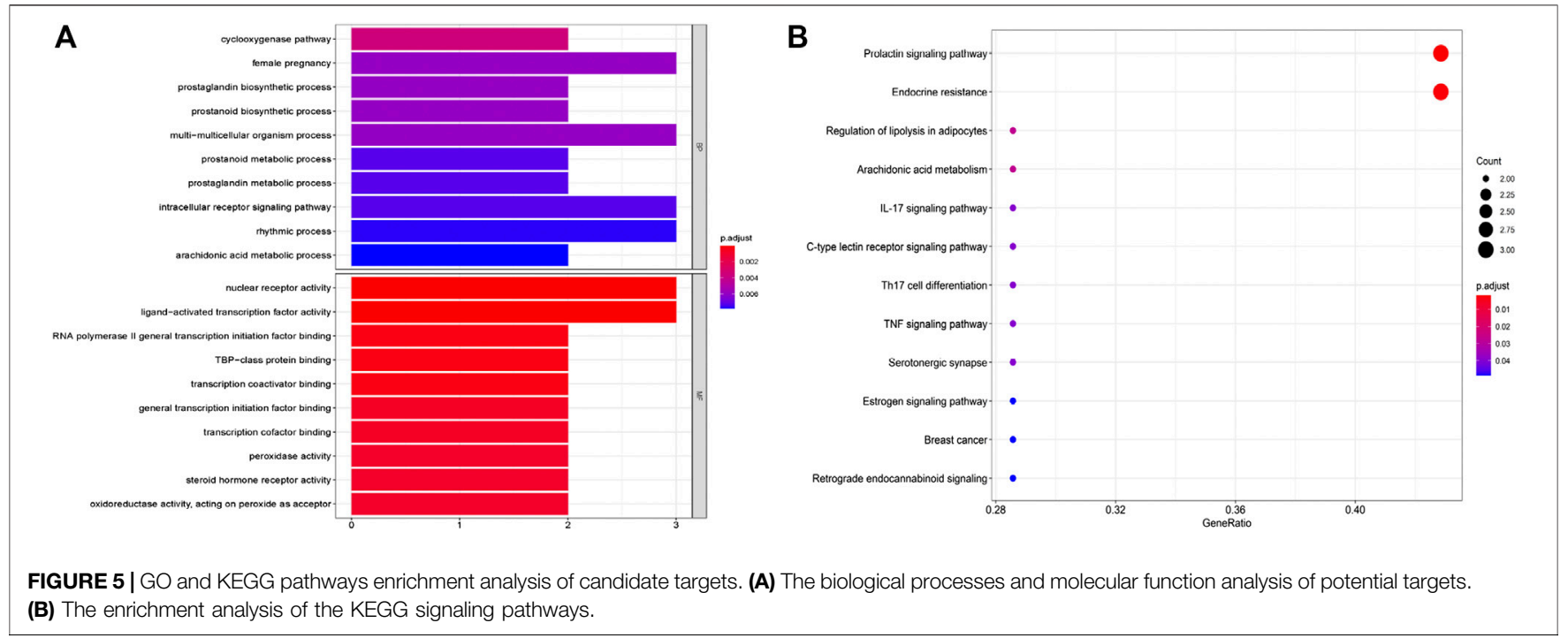

\section{A}

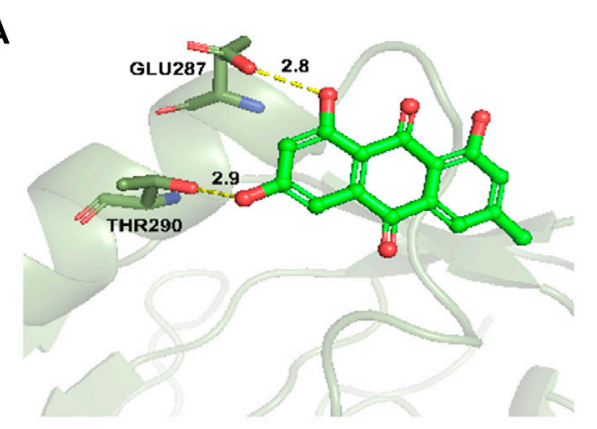

C

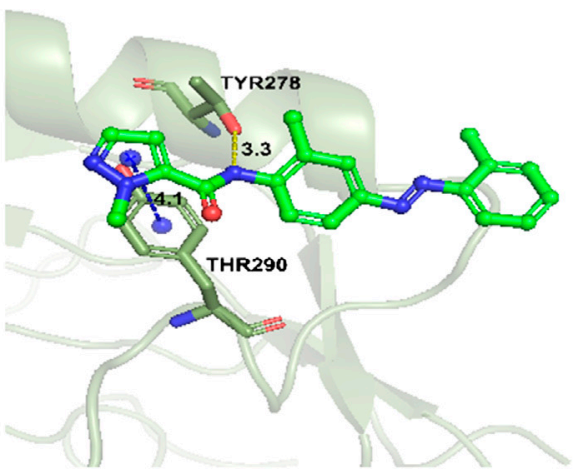

B

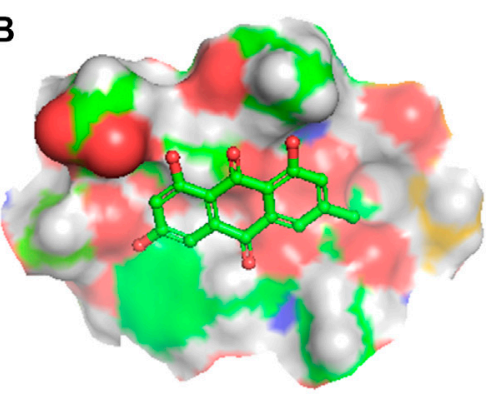

D

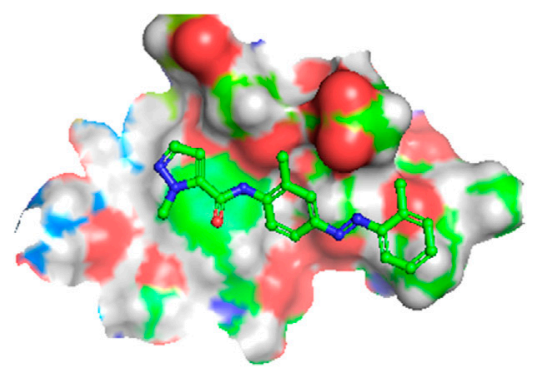

FIGURE 6 | Docking and binding pattern into AhR active site for compounds emodin (A,B), AhR inhibitor CH223191 (C,D). Hydrogen bonds-yellow lines, Pication-blue lines.

\section{Molecular Docking Study}

To explore the binding mode of emodin and $\mathrm{CH} 223191$ with AhR, a molecular docking study was performed using Glide modules of Schrödinger suite 2009 (Schrödinger LLC, New
York, United States). The 3D crystal structure of HIF2a (PDB ID: $3 \mathrm{~F} 1 \mathrm{O}$ ) was used for this docking study. Initially, the protein was also docked with $\mathrm{CH} 223191$ to perform the verification process, after which emodin was docked using the same 

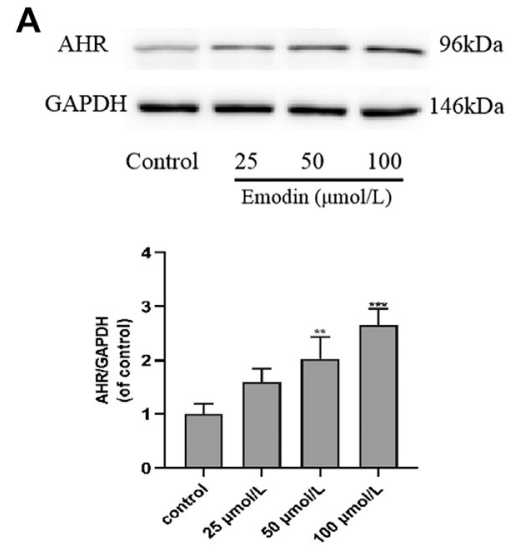

C
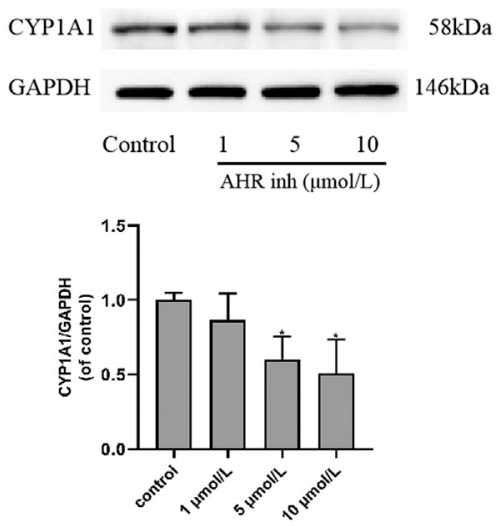

B
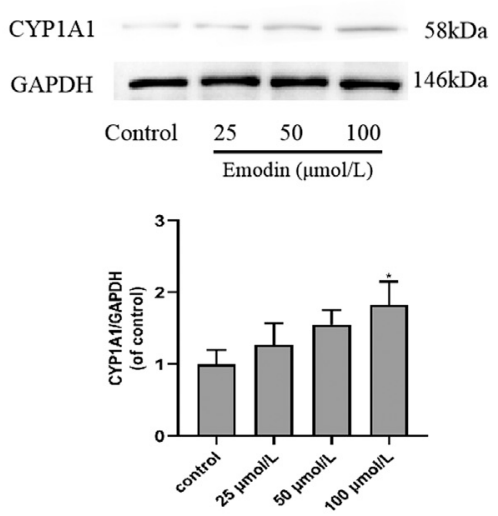

D
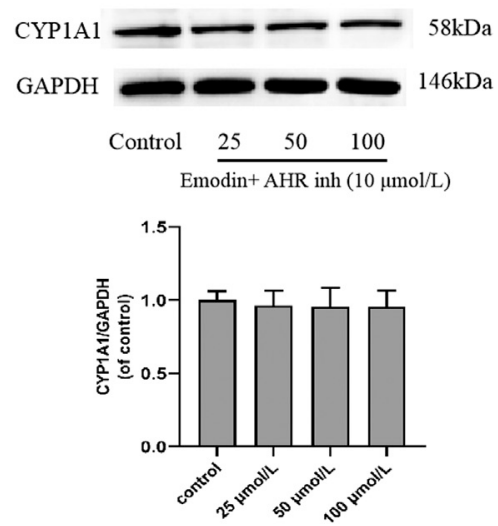

FIGURE 7 | Effects of emodin and AhR inhibitor CH223191 on the protein expression levels of AhR and CYP1A1 in MCF-7 cells (mean \pm SD, $n=3$ ) (A) In the cells treated with emodin, the expression of AhR protein using GAPDH as a loading control and the graphical representations of the AhR/GAPDH ratio; (B) In the cells treated with emodin, the expression of CYP1A1 protein using GAPDH as a loading control and the graphical representations of the CYP1A1/GAPDH ratio; (C) In the cells treated with $\mathrm{CH} 223191$, the expression of CYP1A1 protein using GAPDH as a loading control and the graphical representations of the CYP1A1/GAPDH ratio; (D) In the cells intervened with emodin and $10 \mu \mathrm{mol} / \mathrm{L}$ of $\mathrm{CH} 223191$, the expression of CYP1A1 protein using GAPDH as a loading control and the graphical representations of the CYP1A1/GAPDH ratio.

protocol. The binding mode of emodin is pictured in Figure 6A,B and that of $\mathrm{CH} 223191$ is pictured in Figure 6C,D. Visual inspection of the results indicated that emodin was embedded into the ATP binding pocket of the AhR protein. Moreover, two hydrogen bonds formed within the active binding site of AhR: the AhR Glu 287 residue with the $\mathrm{OH}$-group of emodin and the AhR Thr 290 residue with the $\mathrm{OH}$-group of emodin. The combination of AhR and $\mathrm{CH} 223191$ showed that one hydrogen bond formed within the active binding site of AhR: the AhR Thr 290 resided with the $\mathrm{N}$-atom of $\mathrm{CH} 223191$. Analysis of the binding mode gave us an explanation for different effects on the AhR activity between the two compounds.

\section{Western Blot Analysis}

MCF-7 cells were incubated with different concentrations of emodin and CH223191 for $24 \mathrm{~h}$, after which expression levels of AhR and CYP1A1 were further studied by western blot. The results showed that $25 \mu \mathrm{mol} / \mathrm{L}$ of emodin could increase the expression of CYP1A1 compared with the control group. CYP1A1 is the downstream target gene of AhR in MCF-7 cells. With increasing emodin concentration, CYP1A1 protein expression also gradually increased $(p<0.05)$, which was consistent with AhR protein expression (Figure 7A,B). When CH223191 was added and its concentration was increased, CYP1A1 expression decreased (Figure 7C), likely because the expression of CYP1A1 in cells is regulated by AhR. To validate this hypothesis, we co-treated cells with emodin and $\mathrm{CH} 223191$. The results suggested that the expression levels of CYP1A1 did not change significantly (Figure 7D). These western blot findings strongly suggested that emodin regulated the expression of $\mathrm{AhR}$ and $\mathrm{CYP} 1 \mathrm{~A} 1$ proteins in MCF-7 cells to inhibit cell proliferation.

\section{DISCUSSION}

This study aimed to investigate the role of AhR in the effects of emodin treatment of MCF-7 breast cancer cells. AhR is a ligand-binding transcription factor that regulates various biological processes (Beischlag et al., 2008; Furness and 
TABLE 3 | Molecular docking studies of compounds emodin and AhR inhibitor $\mathrm{CH} 223191$ with AhR

\begin{tabular}{|c|c|c|c|}
\hline Comp & $\begin{array}{c}\text { Glide } \\
\text { energy } \\
\text { (kcal/mol) }\end{array}$ & $\begin{array}{l}\text { Amino acid residues } \\
\text { (within a radius } \\
\text { of } 4 \hat{\AA} \text { from } \\
\text { bound ligand) }\end{array}$ & $\begin{array}{l}\text { H-bond } \\
\text { formatting } \\
\text { residue } \\
\text { and bonds }\end{array}$ \\
\hline Emodin & -4.064 & $\begin{array}{l}\text { Tyr316, Leu310, Tyr278, Glu279, } \\
\text { Phe280, Tyr281, Hie282, Ala283, } \\
\text { Leu284, Ser286, Glu287, Thr290 }\end{array}$ & $\begin{array}{l}\text { Thr290 }=2.160, \\
\text { Glu287 }=1.840\end{array}$ \\
\hline $\begin{array}{l}\text { AhR } \\
\text { inhibitor }\end{array}$ & -2.740 & $\begin{array}{l}\text { Asp251, Ser276, Tyr278, Glu279, } \\
\text { Tyr291, Hie292, Ala293, Leu294, } \\
\text { Asp295, Ser296, Glu297, Asn298, } \\
\text { Thr290, Lys291, His293, Gln294 }\end{array}$ & Thr290 $=2.460$ \\
\hline
\end{tabular}

Whelan, 2009; Marinkovic et al., 2010; Whelan et al., 2010). Studies have found that many drugs used as AhR activators have certain anti-cancer activities. In our study, emodin treatment resulted in concentration-dependent cell death in MCF-7 cells. The MTT results showed that the survival rate of cells decreased in an emodin concentration-dependent manner. When AhR inhibitor $\mathrm{CH} 223191$ was added, the survival rate of the cells was improved than cell survival rate of emodin alone (Figure 2). The results of flow cytometry showed that emodin treatment increased the apoptosis rate of MCF-7 cells. However, when CH223191 was added with emodin, the apoptosis rate of the cells decreased. AhR protein expression increased in an emodin concentration-dependent manner. However, when CH223191 was added, AhR expression was significantly reduced (Figure 3). These different experimental results all suggested that emodin acted as an agonist of AhR. When AhR is activated, it can effectively inhibit the growth of cancer cells. This is consistent with the results of previous studies. For example, O'Donnell et al. found that raloxifene was used as an AhR activator to selectively induce apoptosis in triple-negative breast cancer cells (O'Donnell et al., 2014). Huang et al. determined that aloe-emodin inhibited breast cancer cell proliferation through inhibition of the estrogen receptor (Huang et al., 2013). Marconett et al. reported that indole-3-carbinol can be used as an AhR agonist to eliminate estrogen receptors to inhibit breast cancer cell proliferation (Marconett et al., 2010).

Many studies have shown that AhR can regulate the expression of CYP1A1 protein (Li et al., 1998; Zhang et al., 2003; Beischlag et al., 2008). CYP450s are a class of phase I enzymes involved in the metabolism of endogenous and exogenous compounds in vivo. They are mainly found in the endoplasmic reticulum of cells and belong to a mixedfunction oxidase system (Wei et al., 1996). CYP1A1 is one of the main cytochrome $\mathrm{P} 450$ enzymes. Of the different reactions catalyzed by CYP1A1, the hydroxylation of the aromatic ring vacancy position is considered to be a sign of cancer. It can induce cancer-causing mutations by forming highly reactive conversion products (Buterin et al., 2000). CYP1A1 plays an important role in the detoxification of environmental carcinogens and the metabolic activation of dietary compounds with cancer preventive activity. The transcriptional activation of the CYP1A1 gene is mediated by chemical substances that bind to the cytosolic receptor AhR (Hankinson, 1995). In our study, western bolt results showed that emodin activates AhR to increase the expression of CYP1A1 protein. When AhR is specifically inhibited, the expression of CYP1A1 protein decreased. On this basis, emodin and $\mathrm{CH} 223191$ were added at the same time, and we found that CYP1A1 expression did not change significantly. These results are consistent with the findings of Wei et al. and Lin et al. (Li et al., 1998; Lin et al., 2003). This suggests that the expression of CYP1A1 protein is indeed regulated by AhR.

Emodin is a flavonoid compound extracted from traditional Chinese medicine rhubarb, polygonum cuspidatum, and aloe (Yang et al., 2014b; Cao et al., 2017). Previous reports have shown that there are other flavonoid compounds that can selectively inhibit breast cancer cells by activating the AhR pathway. The aminoflavonoids studied by Brantley et al. inhibited the growth of breast tumors by activating the AhR target and inhibited a6-integrin (Brantley et al., 2016). Wang et al. showed that $\beta$-naphthol flavonoids act as AhR agonists and can mediate the cell cycle arrest of estrogen receptor-positive breast cancer through AhR-dependent regulation. They thereby have anti-tumor activity against breast cancer (Wang et al., 2014). It is worth noting that these flavonoids are based on their own structural characteristics, chemical nature, and function as an AhR agonist to play an anti-tumor effects. On this basis, we generated a docking model of emodin and AhR to provide a potential explanation for the anti-tumor effects of this drug as an AhR agonist.

However, this study does have some limitations. For example, we only studied one breast cancer cell line (MCF-7) and did not conduct research and discussion on other breast cancer cell lines. In the MCF-7 cell experiments, we clarified that emodin inhibits cell proliferation and induces apoptosis by activating the AhR/ CYP1A1 pathway. On the basis of the research method of network pharmacology, this article can only find the relationship between the target and the disease in the existing databases, but cannot discover new targets. The complex mechanism of action between AhR/CYP1A1 and breast cancer still requires further study.

Overall, emodin may exhibit anti-tumor activity by activating the AhR/CYP1A1 pathway, which lays the foundation for the application of emodin in breast cancer treatment. This research combines network pharmacology methods with molecular docking to screen and determine the targets for the treatment of breast cancer, which provides new ideas for future breast cancer research.

\section{DATA AVAILABILITY STATEMENT}

The original contributions presented in the study are included in the article/Supplementary Material, further inquiries can be directed to the corresponding authors. 


\section{AUTHOR CONTRIBUTIONS}

SM, GH, and NZ conceived of the study. NZ, JW, AS, SH, and YT carried out the experiments and performed the statistical analysis. SM, GH, NZ, and JW performed the coordination and wrote the paper. All authors reviewed and approved the final manuscript.

\section{FUNDING}

This work was supported by national major science and technology special project for "significant new drugs

\section{REFERENCES}

Athanasios, A., Charalampos, V., Vasileios, T., and Ashraf, G. M. (2017). Proteinprotein interaction (PPI) network: recent advances in drug discovery. Curr. Drug Metabol. 18, 5-10. doi:10.2174/138920021801170119204832

Bairoch, A., Apweiler, R., Wu, C. H., Barker, W. C., Boeckmann, B., Ferro, S., et al. (2005). The universal protein resource (UniProt). Nucleic Acids Res. 33, D154-D159. doi:10.1093/nar/gki070

Beischlag, T. V., Luis Morales, J., Hollingshead, B. D., and Perdew, G. H. (2008). The aryl hydrocarbon receptor complex and the control of gene expression. Crit. Rev. Eukaryot. Gene Expr. 18, 207-250. doi:10.1615/critreveukargeneexpr. v18.i3.20

Brantley, T., Callero, M. T., Berardi, N., Campbell, N. E., Rowland, S., Zylstra, H., et al. (2016). AhR ligand Aminoflavone inhibits alpha6-integrin expression and breast cancer sphere-initiating capacity. Canc. Lett. 376, 53-61. doi:10.1016/j. canlet.2016.03.025

Buterin, J., Hess, X., Luneva, Y., Geacintov, Q., Amin, G., Kroth, H., et al. (2000). Unrepaired fjord region polycyclic aromatic hydrocarbon-DNA adducts in ras codon 61 mutational hot spots. Canc. Res. 60, 1849-1856. doi:10.5167/uzh-35868

Cai, Y. J., Niu, Z. J., Chen, Y. P., Hu, J., Shi, Y. Y., Wu, A., et al. (2008). Emodininduced generation of reactive oxygen species inhibits RhoA activation to sensitize gastric carcinoma cells to anoikis. Neoplasia. 10, 41-51. doi:10.1593/ neo.07754

Cao, W., Pu, Y., Tang, L., Shen, J., Chen, W., Kang, Z., et al. (2017). Advances in bio-active constituents, pharmacology and clinical applications of rhubarb. Chin. Med. 12, 36. doi:10.1186/s13020-017-0158-5

Chun-Guang, W., Jun-Qing, Y., Bei-Zhong, L., Dan-Ting, J., Chong, W., Liang, Z., et al. (2010). Anti-tumor activity of emodin against human chronic myelocytic leukemia K562 cell lines in vitro and in vivo. Eur. J. Pharmacol. 627, 33-41. doi:10.1016/j.ejphar.2009.10.035

De Las, T., and Fontanillo, G. (2010). Protein-protein interactions essentials: key concepts to building and analyzing interactome networks. PLoS Comput. Biol. 6, e1000807. doi:10.1371/journal.pcbi.1000807

Eleftheriadis, J., Pissas, M., Antoniadi, I., Liakopoulos, C., and Stefanidis, D. M. (2016). Kynurenine, by activating aryl hydrocarbon receptor, decreases erythropoietin and increases hepcidin production in HepG2 cells: a new mechanism for anemia of inflammation. Exp. Hematol. 44, 60-67. doi:10. 1016/j.exphem.2015.08.010

Friesner, S. G., Murphy, F., Repasky, M. P., Frye, L. L., Greenwood, J. R., Halgren, T. A., et al. (2006). Extra precision glide: docking and scoring incorporating a model of hydrophobic enclosure for protein-ligand complexes. J. Med. Chem. 49, 6177-6196. doi:10.1021/jm051256o

Furness, P., and Whelan, C. (2009). The pleiotropy of dioxin toxicity-xenobiotic misappropriation of the aryl hydrocarbon receptor's alternative physiological roles. Pharmacol. Ther. 124, 336-353. doi:10. 1016/j.pharmthera.2009.09.004

Gaudet, D., and Dessimoz, A. (2017). Gene Ontology: pitfalls, biases, and remedies. Methods Mol. Biol. 1446, 189-205. doi:10.1007/978-1-4939-3743-1_14 development" (2019ZX09721001-006-001), the medical and health science and technology innovation project of Chinese Academy of Medical Science (2019-I2M-1-005) and the major natural science research projects in Anhui Universities (KJ2020ZD011).

\section{ACKNOWLEDGMENTS}

The authors gratefully acknowledge Chinese Academy of Medical Sciences \& Peking Union Medical College Institute of Materia Medica and information technology center for affording the Schrödinger suite 2009.

Gfeller, D., Grosdidier, A., Wirth, M., Daina, A., Michielin, O., and Zoete, V. (2014). SwissTargetPrediction: a web server for target prediction of bioactive small molecules. Nucleic Acids Res. 42, W32-W38. doi:10.1093/nar/gku293

Hankinson, E. (1995). The aryl hydrocarbon receptor complex. Annu. Rev. Pharmacol. Toxicol. 35, 307-340. doi:10.1146/annurev.pa.35.040195.001515

Harder, P. H., Damm, C. Y., Maple, M. C., Wu, Y. T., Reboul, C. H., Xiang, H. Y., et al. (2016). Emodin and aloe-emodin suppress breast cancer cell proliferation through ER a inhibition. J. Chem. Theor. Comput. 12, 281-296. doi:10.1021/acs. jctc. 5 b00864

Huang, M., Huang, R., Chen, S., Lee, H., Yue, X., Wang, W., et al. (2013). Emodin and aloe-emodin suppress breast cancer cell proliferation through ER alpha inhibition. Evid Based Complement Altern. Med. 2013, 376123. doi:10.1155/ 2013/376123

Jia, P., Zheng, A. R., Zhang, C., Zeng, E. P., Zou, J. W., and Chen, F. (2015). Female breast cancer incidence and mortality in 2011, China. J. Thorac. Dis. 7, 1221-1226. doi:10.3978/j.issn.2072-1439.2015.05.15

Khongkow, J. C., Gomes, Y. J., Gong, S. T., Man, J. Y., Tsang, S. C., Zhao, C. M., et al. (2016b). Paclitaxel targets FOXM1 to regulate KIF20A in mitotic catastrophe and breast cancer paclitaxel resistance. Oncogene. 35, 990-1002. doi:10.1038/onc.2015.152

Khongkow, P., Gomes, A. R., Gong, C., Man, E. P., Tsang, J. W., Zhao, F., et al. (2016a). Paclitaxel targets FOXM1 to regulate KIF20A in mitotic catastrophe and breast cancer paclitaxel resistance. Oncogene. 35, 990-1002. doi:10.1038/ onc. 2015.152

Ko, J., Su, P., Lin, H., Jhan, A., Ciou, X., Cheng, C. M., et al. (2010). Suppression of ERCC1 and Rad51 expression through ERK1/2 inactivation is essential in emodin-mediated cytotoxicity in human non-small cell lung cancer cells. Biochem. Pharmacol. 79, 655-664. doi:10.1016/j.bcp.2009.09.024

Li, P., Chan, S. W., Yu, T. H., and Chan, S. W. (2013). Emodin induces cytotoxic effect in human breast carcinoma MCF-7 cell through modulating the expression of apoptosis-related genes. Pharm. Biol. 51, 1175-1181. doi:10. 3109/13880209.2013.782322

Li, W., Liu, P. A., Mao, B. K., Wanga, A. B., and Zhang, X. (2009). Emodin sensitizes paclitaxel-resistant human ovarian cancer cells to paclitaxel-induced apoptosis in vitro. Oncol. Rep. 21, 1605-1610. doi:10.3892/or_00000394

Li, W. Y., Harper, R. Y., Tang, P. H., and Okey, S. W. (1998). Regulation of cytochrome $\mathrm{P} 450$ enzymes by aryl hydrocarbon receptor in human cells: CYP1A2 expression in the LS180 colon carcinoma cell line after treatment with 2,3,7,8-tetrachlorodibenzo-p-dioxin or 3-methylcholanthrene. Biochem. Pharmacol. 56, 599-612. doi:10.1016/s0006-2952(98)00208-1

Lin, J., Hu, Y., and Chang, Z. (2003). Correlation between gene expression of aryl hydrocarbon receptor (AhR), hydrocarbon receptor nuclear translocator (Arnt), cytochromes P4501A1 (CYP1A1) and 1B1 (CYP1B1), and inducibility of CYP1A1 and CYP1B1 in human lymphocytes. Toxicol. Sci. 71, 20-26. doi:10.1093/toxsci/71.1.20

Lu, G. F., Xu, D., Zhao, D., Ke, N., Wei, R. M., Kang, D., et al. (2017). Emodin suppresses proliferation, migration and invasion in ovarian cancer cells by down regulating ILK in vitro and in vivo. OncoTargets Ther. 10, 3579-3589. doi:10.2147/OTT.S138217 
Mangiatordi, C. N., Trisciuzzi, S. N., Alberga, K. M., Denora, T. R., Iacobazzi, L. F., Gadaleta, G. L., et al. (2017). Novel chemotypes targeting tubulin at the colchicine binding site and unbiasing P-glycoprotein. Eur. J. Med. Chem. 139, 792-803. doi:10.1016/j.ejmech.2017.07.037

Marconett, C. N., Sundar, S. N., Poindexter, K. M., Stueve, T. R., Bjeldanes, L. F., and Firestone, G. L. (2010). Indole-3-carbinol triggers aryl hydrocarbon receptor-dependent estrogen receptor (ER)alpha protein degradation in breast cancer cells disrupting an ERalpha-GATA3 transcriptional crossregulatory loop. Mol. Biol. Cell. 21, 1166-1177. doi:10.1091/mbc.e09-080689

Marinkovic, A. B., Pasalic, K. R., Ferencak, Y., Grskovic, E. J., and Stavljenic, M. L. (2010). Dioxins and human toxicity. Arh. Hig. Rada. Toksikol. 61, 445-453. doi:10.2478/10004-1254-61-2010-2024

Mariotto, M., Yabroff, S. A., Shao, S. U., Feuer, V. O., and Brown, A. (2011). Projections of the cost of cancer care in the United States: 2010-2020. J. Natl. Cancer Inst. 103, 117-128. doi:10.1093/jnci/djq495

Miliutina, E. F., Ejaz, D. C., Khan, W. H., Iaroshenko, H. S., Villinger, S. K., Iqbal, J., et al. (2017). Synthesis, alkaline phosphatase inhibition studies and molecular docking of novel derivatives of 4-quinolones. Eur. J. Med. Chem. 126, 408-420. doi:10.1016/j.ejmech.2016.11.036

O’Donnell, L. W., Koch, Y., Bisson, A., Jang, Z., and Kolluri, R. C. (2014). The aryl hydrocarbon receptor mediates raloxifene-induced apoptosis in estrogen receptor-negative hepatoma and breast cancer cells. Cell Death Dis. 5, e1038. doi:10.1038/cddis.2013.549

Pickle, S., Hao, F. J., Jemal, A., Zou, Z., Tiwari, R. C., Ward, E., et al. (2007). A new method of estimating United States and state-level cancer incidence counts for the current calendar year. CA Cancer J. Clin. 57, 30-42. doi:10.3322/canjclin.57. 1.30

Piñeros, R. A., Colombet, R. B., Soerjomataram, M. P., Mathers, L. L., Parkin, J. R., Pineros, T. A., et al. (2019). Estimating the global cancer incidence and mortality in 2018: GLOBOCAN sources and methods. Int. J. Canc. 144, 1941-1953. doi:10.1002/ijc.31937

Rendic, J., and Di Carlo, P. (1997). Human cytochrome P450 enzymes: a status report summarizing their reactions, substrates, inducers, and inhibitors. Drug Metab. Rev. 29, 413-580. doi:10.3109/03602539709037591

Ru, G. M., Li, M., Wang, T., Zhou, R., Li, W., Huang, C., et al. (2014). TCMSP: a database of systems pharmacology for drug discovery from herbal medicines. J. Cheminf. 6, 13. doi:10.1186/1758-2946-6-13

Sastry, J. B., Adzhigirey, B. K., Day, M., Annabhimoju, K. V., and Sherman, S. R. (2013). Protein and ligand preparation: parameters, protocols, and influence on virtual screening enrichments. J. Comput. Aided Mol. Des. 27, 221-234. doi:10. 1007/s10822-013-9644-8

Shaik, J. Q., Palaka, K. P., Penumala, W., Kotapati, M. J., Devineni, S. R., Eadlapalli, S., et al. (2016). Emodin inhibits breast cancer cell proliferation through the ERa-MAPK/Akt-cyclin D1/Bcl-2 signaling pathway. Eur. J. Med. Chem. 107, 219-232. doi:10.1016/j.ejmech.2015.10.046

Sui, Y., Xie, X., Zou, Q., and Xie, Y. (2014). Emodin inhibits breast cancer cell proliferation through the ERalpha-MAPK/Akt-cyclin D1/Bcl-2 signaling pathway. Asian Pac. J. Cancer Prev. APJCP. 15, 6247-6251. doi:10.7314/ apjcp.2014.15.15.6247

Sun, D., Wang, J. H., Zhou, H., Lu, M., Zhang, S., and Chen, M. (2015). Inhibitory effect of emodin on migration, invasion and metastasis of human breast cancer MDA-MB-231 cells in vitro and in vivo. Oncol. Rep. 33, 338-346. doi:10.3892/ or.2014.3585
Szklarczyk, S., Morris, J., Cook, Y., Kuhn, D., Wyder, L., Simonovic, T., et al. (2017) The STRING database in 2017: quality-controlled protein-protein association networks, made broadly accessible. Nucleic Acids Res. 45, D362-D368. doi:10. 1093/nar/gkw937

Tian, C., Wang, C. X., Li, Y., Li, K. M., Xu, S. A., and Hou, T. (2015). The application of in silico drug-likeness predictions in pharmaceutical research. Adv. Drug Deliv. Rev. 86, 2-10. doi:10.1016/j.addr.2015.01.009

Wang, Q., Shen, J., Wang, L., Li, M. L., Zhang, H., Liu, W. K., et al. (2017). PharmMapper 2017 update: a web server for potential drug target identification with a comprehensive target pharmacophore database. Nucleic Acids Res. 45, W356-W360. doi:10.1093/nar/gkx374

Wang, X., Xu, Y., Bu, S., Bottum, S., and Tischkau, W. (2014). Beta-naphthoflavone (DB06732) mediates estrogen receptor-positive breast cancer cell cycle arrest through AhR-dependent regulation of PI3K/AKT and MAPK/ERK signaling. Carcinogenesis 35, 703-713. doi:10.1093/carcin/bgt356

Wei, F., Gu, N., Cheng, S. G., Bondy, M. L., Jiang, A., Hong, W. K., et al. (1996). Benzo(a)pyrene diol epoxide-induced chromosomal aberrations and risk of lung cancer. Canc. Res. 56, 3975-3979.

Whelan, J. Y., Hao, G. P., Furness, J. P., Whitelaw, L. Z., and Chapman-Smith, P. (2010). Amino acid substitutions in the aryl hydrocarbon receptor ligand binding domain reveal $\mathrm{YH} 439$ as an atypical AhR activator. Mol. Pharmacol. 77, e0144781-46. doi:10.1124/mol.109.062927

Xing, F., Song, P. W., Deng, Y. Q., Jiang, Z. M., Xiong, P., Yang, B. J., et al. (2015). Antitumor effects and mechanism of novel emodin rhamnoside derivatives against human cancer cells in vitro. PloS One 10, e0144781. doi:10.1371/journal. pone. 0144781

Yang, F., Yuan, P. W., Hao, Y. Q., and Lu, Z. M. (2014a). Emodin enhances osteogenesis and inhibits adipogenesis. BMC Compl. Altern. Med. 14, 74. doi:10. 1186/1472-6882-14-74

Yang, G., Yuan, H., Hao, K., and Lu, Y. (2014b). Emodin enhances osteogenesis and inhibits adipogenesis. BMC Compl. Altern. Med. 14, 74. doi:10.1186/1472-688214-74

Zhang, C., Qin, M., and Safe, H. (2003). Flavonoids as aryl hydrocarbon receptor agonists/antagonists: effects of structure and cell context. Environ. Health Perspect. 111, 1877-1882. doi:10.1289/ehp.6322

Zhang, S., Wang, C., Zhu, S. H., Yang, Y., Li, J., Jiang, H., et al. (2019). Investigation of candidate molecular biomarkers for expression profile analysis of the Gene expression omnibus (GEO) in acute lymphocytic leukemia (ALL). Biomed. Pharmacother. 120, 109530. doi:10.1016/j.biopha.2019.109530

Zu, C., Zhang, M., Xue, H., Cai, X., Zhao, L., He, A., et al. (2015). Emodin induces apoptosis of human breast cancer cells by modulating the expression of apoptosis-related genes. Oncol. Lett. 10, 2919-2924. doi:10.3892/ol.2015.3646

Conflict of Interest: The authors declare that the research was conducted in the absence of any commercial or financial relationships that could be construed as a potential conflict of interest.

Copyright ( 2021 Zhang, Wang, Sheng, Huang, Tang, Ma and Hong. This is an open-access article distributed under the terms of the Creative Commons Attribution License (CC BY). The use, distribution or reproduction in other forums is permitted, provided the original author(s) and the copyright owner(s) are credited and that the original publication in this journal is cited, in accordance with accepted academic practice. No use, distribution or reproduction is permitted which does not comply with these terms. 